\title{
Acute Scrotum in Children:A Review Article
}

\author{
Volkan Sarper Erikci* and Tunç Özdemir
}

Associate Professor of Pediatric Surgery, Sağlık Bilimleri University, Department of Pediatric Surgery, Tepecik Research and Training Hospital, Izmir, Turkey

Received: 漹April 03, 2018; Published: 制 April 16, 2018

*Corresponding author: Volkan Sarper Erikci, Associate Professor of Pediatric Surgery, Dept. Pediatric Surgery, Saglik Bilimleri University, Tepecik Training Hospital, İzmir, Turkey

\section{Abstract}

Acute scrotal conditions are common clinical concern in infants and children. The true cause is difficult to determine. There are several etiologic factors for this syndrome. These are torsion of the testis (TT), torsion of the testicular appendix (TTA), epididymoorchitis (EO) and strangulated inguinoscrotal hernia (SIH). It is generally admitted that EO is rare in children and is associated with structural anomalies of the urinary tract. The aim of this study is to review the various causes of pediatric acute scrotal conditions and to assess management of these patients under the light of relevant literature.

Keywords: Scrotum; Epididiymo-Orchitis, Strangulated İnguinal Hernia; Testis Torsion; Torsion of Testicular Appendage; Torsion of an Epididymal Cyst; EC: Epididymal Cyts

Abbreviations: TT: Torsion of the Testis; TTA: Testicular Appendix; EO: Epididymo-Orchitis; SIH: Strangulated İnguinoscrotal Hernia

\section{Introduction}

Acute scrotal conditions are common in children. It presents with scrotal pain, swelling, redness in the affected hemiscrotum. The true cause is difficult to determine. There are myriad etiologies for this syndrome and these are torsion of the testis (TT), torsion of the testicular appendix (TTA), epididymo-orchitis (EO) and strangulated inguinoscrotal hernia (SIH) [1-3]. General belief is that EO is rare in children and is associated with structural anomalies of the urinary tract [4-6]. The aim of this study is to review the various causes of pediatric acute scrotal conditions and to assess management of these patients under the light of relevant literature. Every boy with acute onset scrotal pain and swelling requires immediate evaluation. Commonest causes of acute scrotum in children are TT, EO, TTA [1-3,7]. Various incidences have been reported regarding the etiology of pediatric acute scrotum [1-3]. True incidence of these causes in acute scrotum is unclear, EO is thought to be uncommon [8].

Traditional teaching suggests that EO is rare in children and occurs more frequently among late adolescents $[2,3,5,9,10]$. Contrary to these previously published reports, it has been reported that only $22.7 \%$ of patients with EO were found to be around peripubertal age group [11]. The incidence of positive urinalysis
(13.6\%) in Erikci's series [11] shows similarity with those reported previously, incidences of which were between 15\%-59\% [2,5,1214]. However, urine culture proven infection rate of $51.6 \%$ has also been reported in children with epididymitis [15]. An associated urologic abnormality should be kept in mind in these patients. In a recent series [11] the incidence of underlying urogenital anomaly in patients with EO was reported to be $22.7 \%$ showing similarity with previous reports $[5,16,17]$. There is controversy if all the patients with EO should undergo investigation of the urinary tract. It has been recommended that all boys with EO should be evaluated for urogenital anomalies [3]. Others suggest further urological assessment only in children with high risk of urinary anomalies $[1,7,17]$. On the other hand it was reported that selective use of VCUG and renal scintigraphs was possible in these patients with the aid of routine urinalysis and urine culture with urinary USG and this was found to be cost effective [11].

SIH is another clinical entity that should be in the differential diagnosis of acute scrotum in children. There are reports with varying incidences of $\mathrm{SIH}$ in pediatric acute scrotum. In a large series of 1228 children with acute scrotum, the incidence of SIH was reported to be lower than $7 \%$ [16]. However the incidence 
of up to $49 \%$ has also been reported [18]. In a recent series the incidence of SIH was found to be $32.7 \%$ [11] showing similarity to Tabari's series [19]. The average age of patients with SIH in Erikci's series was 1.9 years (22 days-10 years) and half of them were in the newborn period and $81.2 \%$ of the patients presented with right sided hernias [11]. So, it is highly recommended that SIH should be kept in mind if a newborn patient presents symptoms compatible with acute scrotum. Testicular torsion is an urgent condition, which requires prompt surgical treatment. In addition to duration, the degree of rotation has been implicated in the clinical outcome [20-22]. Ischemia can ocur as soon as 4 hours after torsion and is almost certain after 24 hours [23]. It was reported that if detorsion occurred less than 6 hours or after 24 hours, testicular salvage rates of $90 \%$ and less than $10 \%$ could be achieved, respectively [24]. In Sidler's series orchiectomy was performed in $61.2 \%$ within 24 to 48 hours of clinical onset [1]. In Erikci's series, with regard to testicular salvage, a rather low rate of $27.3 \%$ (3 out of 11 ) was explained by the late diagnosis and treatment [11]. Some patients with a prolonged period of symptoms may have had intermittent torsion or a partial torsion that testes may be salvageable. So surgery should never be delayed on the assumption of nonviability based on clinical estimate of duration of torsion. Testes in these patients can be salvaged by surgical treatment despite rather long duration of symptoms.

TTA is one of the most frequent causes of acute scrotum. Although it is a benign condition and the necrotic tissue is reabsorbed without any sequelae in almost all cases, the clinical presentation is a major challenge to clinicians. Most of these cases are managed conservatively. The incidence of TTA in patients with acute scrotum varies. In a recents series it was reported to be $2 \%$ [11] which was lower than previous reports $[8,15]$. This finding was explained by relative low percentage of TTA in acute scrotum patients or underdiagnosis of this clinical entity.

Another rare cause of acute crotum in children is torsion of an epididymal cyst. Epididymal cyts (EC) in children are usually benign lesions [25]. Torsion of an EC is extremely rare. A child known to have EC previously may be a candidate of an acute scrotal condition and the twist of EC on its pedicle may produce symptoms resembling acute testicular torsion [26]. In the case of occurrence, surgical excision becomes a matter of necessity rather than of choice since surgical excision promptly resolve the intractable scrotal pain produced by the torsed EC.

\section{Conclusion}

In conclusion, the most common cause of acute scrotum are O/EO, SIH, TT and TTA. After investigations immediate surgical treatment in acute scrotum patients except O/EO is necessary. With this timely approach, it is anticipated that complication rates and salvage of affected testes be decreased. Besides associated urological anomalies should be searched in patients with $0 / \mathrm{EO}$ and in order to protect the upper urinary system, urinary tract infection should be treated.

\section{References}

1. Sidler D, Brown RA, Millar AJW, Rode H, Cywes S (1997) A-25 year review of the acute scrotum in children. S Afr Med J 87(12): 1696-1698.

2. Kaddish HA, Bolte RG (1998) A retrospective review of pediatric patients with epididymitis, testicular torsion and torsion of testicular appendages. Pediatrics 102(1 Pt 1): 73-76.

3. Lewis AG, Bukowski TP, Jarvis PD, Wacksman J, Sheldon CA (1995) Evaluation of acute scrotum in the emergency department. J Pediatr Surg 30(2): 277-282.

4. Merlini E, Rotundi F, Seymandi PL, Canning DA (1998) Acute epididymitis and urinary tract anomalies in children. Scand J Urol Nephrol 32(4): 273-275.

5. Siegel A, Snyder H, Duckett JW (1987) Epididymitis in infants and boys: underlying urogenital anomalies and efficacy of imaging modalities. J Urol 138(4 Pt 2): 1100-1103.

6. Likitnukul S, McCracken GH, Nelson JD, Votteler TP (1987) Epididymitis in children and adolescents. A 20-year retrospective study. Am J Dis Child 141: 41-45.

7. Burgher SW (1998) Acure scrotal pain. Emerg Med Clin North Am 16(4): 781-809.

8. McAndrew HF, Pemberton R, Kikiros CS, Gollow I (2002) Pediatr Surg Int 18: 435-437.

9. Anderson MM, Neinstein LS (1996) Scrotal disorders. In: Adolescent Health care: A Practical Guide, Neinstein LS. (Ed), Williams\&Wilkins, Baltimore. p.464

10. Pillai SB, Besner GE (1998) Pediatric testicular problems. Pediatr Clin North Am 45(4): 813-830.

11. Erikci V, Hoşgör M, Aksoy N, Okur Ö, Yildiz M, et al. (2013) Treatment of acute scrotum in children: 5 years' experience. Ulus Travma Acil Cerrahi Derg 19(4): 333-336

12. Gislason T, Noronha RF, Gregory JG (1980) Acute epididymitis in boys: a 5-year retrospective study. J Urol 124(4): 533-534.

13. Graumann LA, Dietz HG, Stehr M (2010) Urinalysis in children with epididymitis. Eur J Pediatr Surg 20(4): 247-249.

14. Haecker FM, Hauri-Hohl A, von Schweinitz D (2005) Acute epididymitis in children: a 4-year retrospective study. Eur J Pediatr Surg 15(3): 180186.

15. Glabeke EV, Khairouni A, Larroquet M, Audry G, Gruner M (1999) Acute scrotal pain in children: results of 543 surgical explorations. Pediatr Surg Int 15(5-6): 353-357.

16. Yang C, Song B, Liu X, Wei GH, Lin T, et al. (2011) Acute scrotum in children: an 18-year retrospective study. Pediatric Emergency Care 27(4): 270-274.

17. Clift VL, Hutson JM (1989) The acute scrotum in childhood. Pediatr Surg Int $4: 185-188$.

18. Gnassingbe K, Akakpo Numado GK, Songne GB, Anoukoum T, Sakiye KA, et al. (2009) Acute scrotum in children. Mali Med 24(3): 31-35.

19. Tabari AK, Mirshermirani A, Rouzrokh M, Mahmudi M, Baghaiepour MR, et al. (2010) Early exploration in the management of acute scrotum in children. Iran J Pediatr 20(4): 466-470.

20. Heindel RM, Pakyz RE, Reinking LN, Cosentino MJ (1990) The effect of various degrees of unilateral spermatic cord torsion on fertility in the rat. J Urol 144(2 Pt 1): 366-369.

21. Sonda LP Jr, Lapides J (1961) Experimental torsion of the spermatic cord. Surg Forum 12: 502-504. 
22. Tryfonas G, Violaki A, Tsikopoulos G, Avtzoglou P, Zioutis J, et al. (1994) Late postoperative results in males treated for testicular torsion during childhood. J Pediatr Surg 29(4): 553-556.

23. Ringdahl E, Teague L (2006) Testicular torsion. Am Fam Physician 74(10): 1739-1743.

24. Davenport M (1996) ABC of general surgery in children. Acute problems of the scrotum. BMJ 312(7028): 435-437.
25. Erikci V, Hoșgör M, Aksoy N, Okur Ö, Yildiz M, et al. (2013) Management of epididymal cysts in childhood. J Pediatr Surg 48(10): 2153-2156.

26. Erikci V, Hosgör M, Yildiz M, Aksoy N, Okur Ö, et al. (2013) Torsion of an epididymal cyst: a case report and a review of the literature. Turk J Pediatr 55(6): 659-661.
(C) Commons Attribution 4.0 License

To Submit Your Article Click Here: Submit Article

DOI: $10.32474 /$ PAPN.2018.01.000114

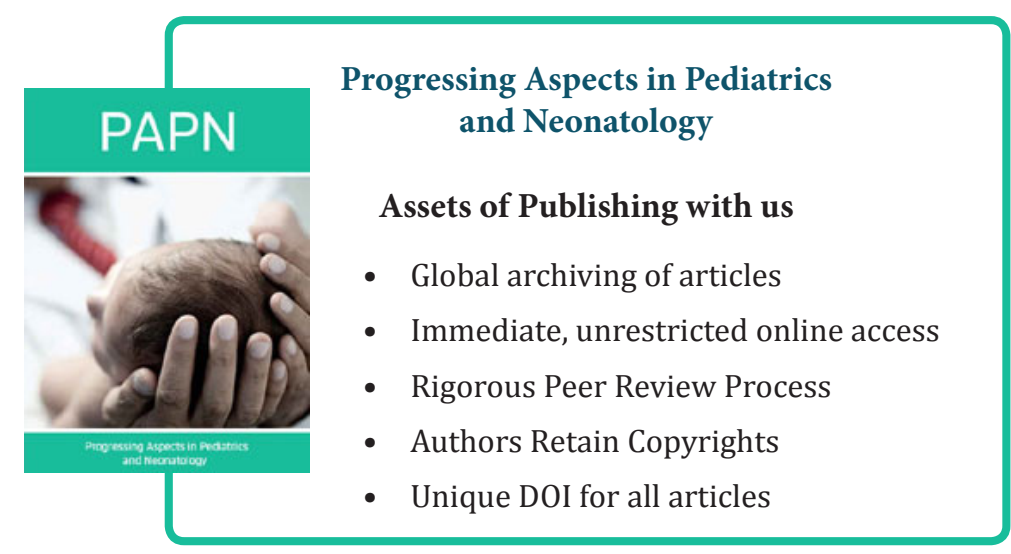

